\title{
Estandarización de una prueba de inmunofluorescencia indirecta para IgG anti-Toxoplasma en ratón
}

\author{
Miriam Consuelo López ${ }^{1}$, Augusto Corredor ${ }^{1}$, Patricia Reyes ${ }^{1}$, Alejandro Giraldo ${ }^{2}$, \\ Dora Fonseca $^{2}$, Jorge Enrique Gómez ${ }^{1,3}$ \\ 1 Unidad de Parasitología, Departamento de Salud Pública y Tropical e Instituto de Salud en el Trópico, \\ Facultad de Medicina, Universidad Nacional de Colombia, Bogotá, D.C., Colombia. \\ ${ }^{2}$ Fundación Gillow, Bogotá, D.C., Colombia. \\ ${ }^{3}$ Centro de Investigaciones Biomédicas, Facultad de Ciencias de la Salud, Universidad del Quindío, \\ Armenia, Colombia.
}

\begin{abstract}
Se describe una técnica de inmunofluorescencia indirecta (IFI) para la detección de IgG antiToxoplasma en ratón. La técnica reveló infecciones en el ratón a partir de inoculaciones de 10 taquizoitos de Toxoplasma gondii. En muestras de pacientes, se detectó infección en un líquido amniótico de una paciente con toxoplasmosis adquirida en el embarazo y en un líquido cefalorraquídeo de una paciente con toxoplasmosis cerebral. La técnica de inoculación en ratón y su detección por IFI es un complemento para el diagnóstico en el líquido amniótico o en el inmunosuprimido y es una herramienta valiosa para el aislamiento y caracterización de cepas de Toxoplasma.
\end{abstract}

Palabras clave: Toxoplasma, IFI, IgG.

\section{Standardization of an IFAT for IgG anti-Toxoplasma in mice}

We describe a technique based on indirect immunoflurescence antibody test (IFAT) for detection of specific anti-Toxoplasma lgG in mice. This technique detected infection from inocula with 10 tachyzoites of Toxoplasma in albino mice. In samples from human patients, this technique detected infection in amniotic fluid and in central nervous sample fluid. IFAT for IgG antiToxoplasma in mice is a useful complementary technique for the diagnosis of toxoplasmosis.

Key words: Toxoplasma, IFAT, IgG.

El aislamiento de Toxoplasma a partir de muestras clínicas se puede realizar en cultivo celular o en ratón. Los estudios de otros autores han demostrado que el cultivo celular no es tan sensible y, de otra parte, es mucho más costoso que la inoculación en ratón (1-3). Las cepas provenientes de muestras humanas tienen la tendencia de volverse crónicas en el ratón y no dan síntomas en el animal; por lo tanto, se hace necesario utilizar una prueba serológica que testifique la infección en el ratón. La aparición de

Correspondencia:

Jorge E. Gómez, Centro de Investigaciones Biomédicas, Facultad de Ciencias, Universidad del Quindío, Armenia, Colombia.

Recibido: 11/04/00; aceptado: 27/10/00 anticuerpos detectables tiene lugar 4 semanas después de la inoculación, si la muestra contiene Toxoplasma. El objetivo del presente trabajo fue estandarizar una prueba de determinación de anticuerpos IgG anti-Toxoplasma en el ratón. De otra parte, se inocularon muestras humanas con el fin de demostrar su potencial utilidad. Este trabajo no pretende hacer una evaluación de la herramienta diagnóstica sino establecer las condiciones técnicas para su realización.

\section{Materiales y métodos}

\section{Ratones}

Se utilizaron ratones blancos suizos, cepa ICR, de 21 días de nacidos, suministrados por el Bioterio del Instituto Nacional de Salud. 


\section{Parásito}

Se utilizó la cepa RH de Toxoplasma gondii donada por el Laboratorio de Parasitología del Instituto Nacional de Salud. Esta cepa se conservó en nitrógeno líquido y, luego, se adaptó por pases sucesivos en ratón blanco suizo por inoculación intraperitoneal.

\section{Conjugado}

Se usó IgG de cabra anti-Fab de la IgG de ratón conjugada a fluoresceína, ref. F5262 de Sigma (USA) y prueba de inmunofluorescencia indirecta (IFI-lgG)para ratón.

Se obtuvo sangre de la cola del ratón antes de la inoculación de la dosis de taquizoitos que se recolectó en papel filtro y por punción cardlaca a las 4 semanas post-inoculación. El suero de cada ratón se probó en 7 diluciones: 1:2, 1:4, 1:8, 1:16, $1: 32,1: 64$ y $1: 128$. Se incubó durante 20 minutos sobre láminas de vidrio que contenían taquizoitos previamente fijados por calor. Se realizaron 3 lavados con tampón PBS, pH 7,2. El conjugado se utilizó en una dilución 1:120 y se incubó 20 minutos y luego se hicieron 3 lavados con PBS, $\mathrm{pH} 7,2$, y un último lavado con agua destilada. Se observó la fluorescencia en un microscopio de luz ultravioleta marca Nikon. Se consideró presencia de anticuerpos específicos cuando había fluorescencia alrededor de todo el taquizoito de la placa.

\section{Prueba de inmunofluorescencia indirecta para IgG en humanos}

Se utilizó la técnica de IFI (inmunofluorescencia indirecta) para estudiar la frecuencia de IgG antiToxoplasma según los métodos del Instituto Nacional de Salud de Colombia (4). Brevemente, se obtienen taquizoitos de T. gondii del exudado peritoneal de ratones y se fijan con formaldehído sobre láminas de vidrio. Se prueban diluciones al doble del suero, las cuales se incuban durante 1 hora y se lavan dos veces con solución de fosfato salina $150 \mathrm{mM}(\mathrm{pH} \mathrm{7,2)} \mathrm{y,} \mathrm{luego,} \mathrm{se} \mathrm{incuban} \mathrm{con}$ el conjugado de isotiocianato de fluoresceína (Fluoline H, Biomérieux) diluido 1:320. El resultado de una prueba por IFI-IgG se consideraba reactivo cuando aparecía una fluorescencia que rodeaba por entero el parásito a partir de una dilución del suero en 1:16.

\section{Muestras de pacientes con toxoplasmosis}

Se recolectaron 17 muestras de líquido amniótico de gestantes con toxoplasmosis adquirida durante el embarazo según criterios serológicos (aumento de títulos de lgG en muestras pareadas o presencia de IgM anti-Toxoplasma). Todas las muestras se sometieron a prueba de PCR para el gen B1 de Toxoplasma realizada en la Fundación Gillow de Bogotá. Además, se inoculó una muestra de LCR de un paciente inmunosuprimido con toxoplasmosis cerebral. EI LCR del paciente presentaba títulos de anticuerpos IgG anti-Toxoplasma de 1:512. De las muestras de líquido amniótico, se recibió $1 \mathrm{ml}$ con el cual se inocularon intraperitonealmente dos ratones, cada uno con $0,5 \mathrm{ml}$ y un ratón control negativo con solución salina. EI LCR del paciente con toxoplasmosis cerebral se inoculó directamente en tres ratones a razón de $0,5 \mathrm{ml}$ por vía intraperitoneal para cada ratón. Los ratones fueron sangrados previamente de la cola y por punción cardiaca a las 4 semanas. Sí el ratón presentaba síntomas, se realizaba una segunda inoculación con homogenizado de cerebro y bazo.

\section{Resultados}

\section{Grupos de infección experimental en ratón}

Se probaron 4 dosis de inóculo de taquizoitos de $T$. gondii de la cepa de referencia $\mathrm{RH}$. Para este fin, se conformaron 4 grupos de ratones, cada uno en un cubículo diferente. En cada cubículo había 3 ratones inoculados con la misma dosis $(3,10$, 15 ○ 25 taquizoitos) y un ratón inoculado con solución salina (control negativo). Los resultados de la fluorescencia se muestran en la figura 1. La técnica fue positiva en ratones inoculados con 10

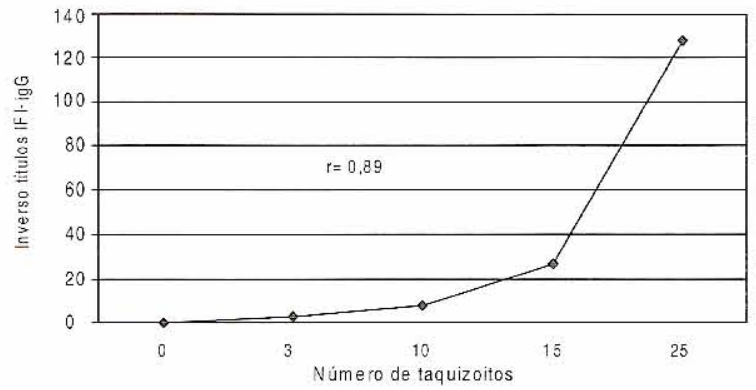

Figura 1. Anti-Toxoplasma según la dosis del inóculo de taquizoitos. 
o más taquizoitos. El coeficiente de correlación entre la dosis inoculada y el inverso de títulos fue de 0,89 , lo cual demuestra una relación directamente proporcional entre la dosis de taquizoitos y el inverso de los títulos de anticuerpos IgG en el ratón.

\section{Resultados con muestras de pacientes}

De 17 líquidos amnióticos, sólo una muestra fue reactiva en los dos ratones inoculados. Ambos presentaron un título de anticuerpos IgG anti-Toxoplasma idéntico, 1:32. Todos los sueros preinoculación de cada ratón fueron negativos, así como todos los controles inoculados con solución salina. Cada control negativo permaneció en la misma jaula que los ratones inoculados con las muestras de los pacientes. Dos de los tres ratones inoculados con el LCR murieron a los 21 días de inoculación. El tercer ratón se dejó en observación, no presentó síntomas y se sacrificó a los dos meses post-inoculación. El cerebro, el bazo y el hígado de este último ratón se homogenizaron en un homogenizador de tejido con solución salina, se filtraron en gasa y el filtrado se reinoculó: el de bazo e hígado en un ratón y el de cerebro en otro. A las cuatro semanas, se recolectó sangre por punción cardiaca y el suero presentó títulos de IFI-IgG anti-Toxoplasma de 1:8 en los dos ratones.

\section{Discusión}

El cultivo en ratón es un complemento necesario para el diagnóstico de la toxoplasmosis tanto en la forma congénita como en el inmunosuprimido $(1,2)$. En el caso del diagnóstico prenatal de la toxoplasmosis congénita, dos estudios recientes con muestras amplias de pacientes han clarificado la situación planteada en estudios iniciales sobre la utilidad del PCR $(1,5)$. El PCR en líquido amniótico tuvo una sensibilidad de 80 a $90 \%$ y el cultivo en ratón de 50 a $60 \%$. Aunque el PCR es más sensible, siempre se debe combinar con la inoculación en ratón pues se ha demostrado que, en ocasiones, la única prueba que da resultado positivo en un niño infectado puede ser la inoculación en ratón, mientras que la prueba de PCR es negativa en la misma muestra. La combinación de las dos técnicas eleva la sensibilidad de detección a 90-95\% $(1,5)$. Como se puede constatar, hay un porcentaje de niños (5 a 10\%) que no son diagnosticados prenatalmente, así que de todas maneras todo hijo de madre con evidencia serológica de riesgo de infección toxoplásmica debe seguirse postnatalmente.

Hemos estandarizado y demostrado la utilidad de la técnica y el nivel de sensibilidad de ella. La curva de relación entre dosis de taquizoitos y títulos de anticuerpos demuestra una relación directamente proporcional $(r=0,89)$ y muestra la sensibilidad de la técnica, pues se detectó infección a partir de 10 taquizoitos inoculados. Es interesante anotar los hallazgos en el caso de las muestras de pacientes. En el caso de la gestante, la inoculación en ratón fue positiva mientras que la PCR fue negativa. Esto concuerda con lo reportado recientemente por otros autores $(1,4)$. Se piensa que los falsos negativos en el PCR se pueden deber a la presencia de inhibidores de la enzima taq polimerasa o a que se inocula mayor volumen en el ratón. En el caso del inmunosuprimido, la inoculación en el ratón fue positiva. Esto es llamativo dada la dificultad en lograr aislamientos en el caso de los pacientes infectados por VIH, lo cual se logra sólo en 20$30 \%$ de casos (2). En nuestro caso, pudo contribuir una carga excesiva de parásitos, como lo sugiere el alto título de anticuerpos en LCR. El título más alto que habíamos encontrado previamente era de 1:32.

Esperamos que esta técnica contribuya a determinar en qué momento hemos obtenido una inoculación de Toxoplasma, lo cual es un paso esencial para lograr aislamientos exitosos de la cepas circulantes en nuestro medio.

\section{Agradecimientos}

Este trabajo fue financiado por COLCIENCIAS (proyecto código 1101-04-1012-98) y el DIBUniversidad Nacional de Colombia (proyecto código DIB 709186).

\section{Referencias}

1. Foulon W, Pinon JM, Stray-Pedersen B, Pollak A, Lappalainen M, Decoster A, et al. Prenatal diagnosis of congenital toxoplasmosis: a multicenter evaluation of different diagnostic parameters. Am J Obstet Gynecol 1999;181:843-7. 
2. Diego JA, Vásquez JJ, Penin P, Fernández J, Sánchez S, Gamallo C. Use of murine subinoculation for the diagnosis and isolation of toxoplasmosis in HIVinfected patients with persistent lymphadenopathy. Ann Trop Med 1993;87:179-84.

3. Derouin F, Mazeron MC, Garin YC. Comparative study of tissue culture and mouse inoculation methods for demonstration of Toxoplasma gondii. J Clin Microbiol 1987;25:1597-600.
4. Juliao O, Moreno GS. Manual de técnicas de laboratorio. Bogotá, Colombia: Instituto Nacional de Salud; 1981. p.112-8.

5. Robert-Gagneux F, Gavinet MF, Ancelle T, Raymond J, Tourte-Schaffer C, Dupoy-Camet J. Value of prenatal diagnosis and early postnatal diagnosis of congenital toxoplasmosis: retrospective study of 110 cases. J Clin Microbiol 1999;37:2893-8. 